\title{
Parametrik hızlandııımış başarısızlık (ölüm) zamanı (HBZ) modelleri ile erken evre meme kanseri hastalarında uygulama
}

\author{
Application of parametric Accelerated Failure Time (AFT) model in early stage breast \\ cancer patients
}

Nural Bekiroğlu, Ayşe Ülgen

Gönderilme tarihi:09.03.2021

Kabul tarihi:26.04.2021

Öz

Amaç: Cox Orantılı Hazard $(\mathrm{COH})$ modeli sağkalım analizinde en sık kullanılan çok değişkenli regresyon modelidir. Ancak uygulamada orantılı hazard $(\mathrm{OH})$ varsayımını sağlamak her zaman mümkün olmamaktadır. Bu durumda Parametrik Hızlandırılmış Başarısızlık (Ölüm) Zamanı (HBZ) modelleri bir seçenek olarak düşünülebilir. $\mathrm{Bu}$ çalışmada $\mathrm{HBZ}$ ve $\mathrm{COH}$ modelleri erken evre meme kanseri tanısı olan hastalara uygulanarak sonuçlar karşılaştırılmıştır.

Gereç ve yöntem: Bu çalışmada 697 erken evre meme kanserli hastanın retrospektif sağkalım verileri analiz edilmiştir. Bağımlı değişken olan genel sağkalım ve 13 bağımsız değişkenle test edilmiştir. Anlamlı çıkan değişkenler çoklu regresyon analizi olan $\mathrm{COH}$ modeli ile yapılan regresyonla tahmin edilmeye çalışılmıştır. HBZ modeli için verilerin olası log-normal, log-lojistik, Weibull ve üstel dağılımlarına ait Hazard Fonksiyonlarına bakılmıştır.

Bulgular: İstatistiksel olarak anlamlı çıkan 9 bağımsız değişkenden; yaş grupları, tümör derecesi, nöral invazyon ve ekstra kapsül tutulumu $\mathrm{COH}$ modelindeki orantılı hazard $(\mathrm{OH})$ varsayımını sağlamamasına rağmen, çok değişkenli $\mathrm{COH}$ modeline girdiğinde sadece metastatik lenf nodu sayısı ve menopoz değişkenleri anlamlı bulunmuştur. Genel sağkalıma ait en uygun hazard fonksiyonu dağılımının Log-lojistik dağılıma uygun olduğu görülmüş ve Log-lojistik HBZ regresyon modeli sonucunda ise metastatik lenf nodu sayısı, menopoz ve tümör boyutu değişkenleri anlamlı çıkmıştır.

Sonuç: Literatürde $\mathrm{COH}$ modeli en sık kullanılan sağkalım modellerinin başında gelir. Hazardların orantılı olmadığı durumlarda $\mathrm{COH}$ regresyon modeli yerine $\mathrm{HBZ}$ regresyon modeli gibi modellerin kullanımı bir seçenek olarak düşünülebilir.

Anahtar kelimeler: Sağkalım analizi, cox orantılı hazard modeli, parametrik hızlandırımış başarısızlık (ölüm) zamanı (HBZ), parametrik orantılı modeli, log-lojistik.

Bekiroğlu N, Ülgen A. Parametrik hızlandırılmış başarısızlık (ölüm) zamanı (HBZ) modelleri ile erken evre meme kanseri hastalarında uygulama. Pam Tıp Derg 2021;14:654-665.

\begin{abstract}
Purpose: Cox Proportional Hazard (CPH) model is the most commonly used multivariate regression model for survival analysis. However, it is not always possible to obtain the proportional hazard (PH) assumption. In this case, Parametric Accelerated Failure Time (AFT) models may be an option. In this study, AFT and CPH models were applied to patients with early stage breast cancer and the results were compared.

Materials and methods: Retrospective survival data of 697 patients with early stage breast cancer were analyzed in this study. 13 independent variables and overall survival time as the dependent variable were tested. Multiple $\mathrm{CPH}$ regression analysis were performed for significant variables. For the AFT model, hazard functions of the data belonging to log-normal, log-logistic, Weibull and of exponential distributions were examined.

Results: Among the 9 independent variables that were statistically significant; although age groups, tumor grade, neural invasion and extra capsule involvement did not satisfy the $\mathrm{CPH}$ assumption, when the multivariate $\mathrm{CPH}$ model was used, only metastatic lymph nodes and menopausal status were found to be significant. It was observed that the most appropriate hazard function distribution of overall survival was suitable for Loglogistic distribution, and as a result of the Log-logistic AFT regression model, metastatic lymph node number, menopause and tumor size were found to be significant.

Conclusion: In the literature, the $\mathrm{CPH}$ model is one of the most commonly used survival models. In cases where the assumption of the proportionality of hazards is violated, AFT regression models may be used as an alternative.
\end{abstract}

Key words: Survival analysis, cox proportional hazard model, accelerated failure time (AFT) model, parametric proportional model, log-logistic.

Nural Bekiroğlu, Prof. Dr. Marmara Üniversitesi, Tıp Fakültesi, Biyoistatistik Anabilim Dalı, İstanbul, Türkiye, e-posta: nural@marmara.edu.tr (https://orcid.org/0000-0001-6471-6612)

Ayşe Ülgen, Dr. Öğr. Üye. Girne Amerikan Üniversitesi, Tıp Fakültesi, Biyoistatistik Anabilim Dalı, Girne, KKTC, e-posta: ayseulgen1@gmail. com (https://orcid.org/0000-0002-0872-667X) (Sorumlu Yazar) 
Bekiroglu N, Ulgen A. Application of parametric Accelerated Failure Time (AFT) model in early stage breast cancer patients. Pam Med J 2021;14:654-665.

\section{Giriş}

Cox Orantılı Hazard (göreli risk) $(\mathrm{COH})$ modeli yarı-parametrik bir model olup, sağkalım verilerine en çok uygulanan çok değişkenli bir regresyon modelidir [1]. Ancak bu modelin uygulanabilmesi için en önemli varsayımlarından biri de Orantılı Hazard $(\mathrm{OH})$ varsayımıdır. Sağkalım analizlerinde bazen Üstel, Weibull, Genelleştirilmiş Gamma, Gompertz, Log-normal, Log-lojistik gibi bazı özel parametrik dağılımlar aracılığı ile Parametrik Orantılı Hazard (POH) modelleri de kullanılmaktadır. Bu modellerin istatistiksel gücünün parametrik olmayan ve yarı-parametrik olan sağkalım modellerine göre daha yüksek olduğu bir gerçektir. Özellikle $\mathrm{POH}$ sağkalım modellerinden elde edilen sağkalım tahminlerine göre çizilen sağkalım eğrilerinin, teorik sağkalım eğrileri kadar tutarlı sonuçlar verdiği bilinmektedir. Ancak bu tür modellerin de aynı $\mathrm{COH}$ modelde olduğu gibi hazardlarının orantılı olması koşulu söz konusudur ve çok değişkenli analizde birçok belirleyicinin ve tüm tahmin edicilerin orantılı hazard varsayımını karşılaması gerekmektedir [2-18].

Ancak $\mathrm{OH}$ varsayımını sağlamak çoğu zaman zordur. Bu varsayımın sağlanamadığı durumlarda parametrik sağkalım modellerinden Parametrik Hızlandırılmış Başarısızlık (Ölüm) Zamanı (HBZ) modelleri uygulamada bir seçenek olarak düşünülebilir $[9,10]$. Bu modelde, parametrelerin tahmin edilmesi ayn $\mathrm{POH}$ modellerinde olduğu gibi güçlüdür ve en önemli özelliği ise $\mathrm{POH}$ modellerindeki gibi kısıtlayıcı bir varsayım olan hazardların orantılı olması gerekliliği yoktur [4]. Bu modellerin diğer bir avantajı da, sonuçların hazardlarını sunarak tartışmak yerine sağkalım zamanları açısından tahminlerin yapılmasıdır. Bu modellerde hazard dağılımları önem taşır ve Parametrik HBZ modellerinde genelde kullanılan dağılımlar Üstel, Weibull, Log-normal, Log-lojistik ve Genelleştirilmiş Gamma modelleridir. Hazardların dağııımı söz konusu dağılımlardan hangisine uyarsa, o dağılımlı HBZ regresyon modeli uygulanır $[15,18]$.

Genelde yapılan yanlış bir uygulama da; $\mathrm{COH}$ modelinin en önemli varsayımı olan orantısallığı sağlamayan ve tek değişkenli analizde anlamlı bulunan bağımsız değişkenlerin çok değişkenli $\mathrm{COH}$ modelinde yer almalarıdır ve dolayısıyla bu durum ilgili değişkenlere ait tahminlerin yorumunda çoğu zaman zorluklar yaratmaktadır. Böyle durumlarda önerilen seçenek yöntemlerden biri de, Hızlandırılmış Başarısızlık (ölüm) Zamanı (HBZ) modelidir. Bu çalışmada; $\mathrm{HBZ}$ ve $\mathrm{COH}$ modelleri kullanılarak bağımsız değişkenler ile ilgili elde edilen sonuçlar karşılaştırılmıştır. Ayrıca hem sağkalım zaman karşılaştırmaları bakımından hem de hazardların karşılaştırmaları bakımından daha geniş ve ayrıntılı bilgi sunulmuştur.

\section{Gereç ve yöntem}

Retrospektif sağkalım verileri, erken evre meme kanseri tanısı olan, Marmara Üniversitesi Tıp Fakültesi'nde teşhis edilmis 697 kadına ait verilerden oluşmaktadır. Araştırma, Marmara Üniversitesi Tıp Fakültesi Klinik Araştırmalar Etik Kurulu'nun onayı ile yapılmıştır. Bağımlı değişken olan genel sağkalım süresi, 13 adet bağımsız değişkenle test edilmiştir. Sağkalım Analizinde tek değişkenli analizler için; kesikli rassal değişkenlerde LogRanktesti, süreklirassal değişkenli verilerde ise Basit Cox Regresyonu uygunlanmıştır. Sağkalım istatistiklerinde tek değişkenli analiz sonrasında anlamlı çıkan değişkenler çoklu regresyon analizi olan Cox Orantılı Hazard modeli ile yapılan regresyonla tahmin edilmeye çalışılmıştır.

Hızlandırımış Başarısızlık Zaman Modelinde ise; verilerin olası log-normal, loglojistik, Weibull ve üstel dağılımlarına ait Hazard Fonksiyonlarına bakılmıştır. En iyi modeli bulmak için modelin uyum iyiliği testi ve Akaike Bilgi Kriteri (AIC) [16-18] değerleri hesaplanmıştır. AIC değerine göre en düşük olan AIC değerli model dikkate alınmıştır. Bu veri seti için en iyi hazard fonksiyonunu, hem grafik hemde AIC değeri bakımından log-lojistik dağılımı vermiştir ve Hızlandırıımış Başarısızlık Zaman Modeli log-lojistik regresyon ile gerçekleştirilmiştir. Veriler STATA 10 ve SPSS 15 istatistiksel paket programlarında analiz edilmiştir ve $p<0,05$ anlamlı sonuç olarak kabul edilmiştir.

\section{Sağkalım regresyon analizi}

Sağkalım regresyon analizinde ise bağımlı 
değişken ile bağımsız değişkenler arasındaki ilişki birkaç yolla modellenebilir;

\section{Yarı-parametrik Orantılı Hazard (OH) regresyon modeli}

\section{- Cox orantılı hazard (göreli risk) (COH)}

Cox metodu, "yarı-parametrik" bir yaklaşımdır. Sağkalım süreleri için herhangi bir özel dağııım tipi varsayılmaz. Ancak önemli bir varsayım; sağkalımdaki değişik değişkenlere ait etkilerin zaman içinde sabit kalmasıdır ki, bu varsayıma Orantılı Hazard $(\mathrm{OH})$ varsayımı denmektedir.

Cox metodu, çok değişkenli bir regresyon modeli çözümlemesi gibidir.

$$
h(t \mid x)=h(t) \exp \left(\beta_{0}+\beta_{1} x_{i 1}+\ldots . . \beta_{p} x_{i p}\right)
$$

Modelin parametrik olmayan kısmını oluşturan $h(t)$ için herhangi bir varsayımda (assumption) bulunulmaz. Ayrica $x_{1}{ }^{\prime}$ den $x_{p}$ 'ye kadar olan bağımsız değişkenlerin hazarda olan etkilerini parametrik olan kısmında varsayar. $\beta_{1}$ 'den $\beta_{p}$ 'ye kadar olan regresyon katsayıları genelde en çok olabilirlik tahmin yöntemiyle tahmin edilen katsayılardır.

\section{Parametrik Orantılı Hazard (POH) regresyon modelleri}

Parametrik Orantılı Hazard ( $\mathrm{POH}$ ) modelinini varsayımları şöyledir;

${ }^{*}(\mathrm{~h}, \mathrm{H}, \mathrm{S})$ gibi temel fonksiyonların gerçek formları doğru bir şekilde belirlenmelidir.

* Bağımsız değişkenlerle "log hazard “ arasındaki ilişki doğrusaldır (lineerdir).

*etkileşimlerin yokluğunda, bağımsız değişkenlere ait kestiriciler log hazard üzerine ek olarak hareket ederler.

* bağımsız değişkenlere ait kestiricilerin etkisi t'nin tüm değerleri için aynıdır.

\section{- Parametrik Orantılı Hazard (POH) modeli}

Oldukça sık kullanılan bir sağkalım regresyon yöntemidir. Genelde üstel, Weibull gibi dağılımlar bu gibi parametrik sağkalım modellerinde kullanılmakta olup $\mathrm{OH}$ varsayımı bu modeller için de geçerlidir.

Bağımsız değişkenler bireyin hazardına etki eder ve regresyon şu şekilde belirlenir;

$$
h(t \mid X)=h(t) \exp (X \beta)
$$

Burada $\mathrm{h}(\mathrm{t})$ temel hazard fonksiyonu olarak ifade edilir ve herhangi bir parametrik tehlike fonksiyonu $\mathrm{h}(\mathrm{t})$ için kullanılabilir.

$\mathrm{Bu}$ parametrik forma bağlı olarak, $X \beta^{\prime}$ ın regresyon sabiti olabilir. $\operatorname{Exp}(X \beta)$ terimi bazen göreli hazard fonksiyonu gibi de adlandırıır. $\mathrm{POH}$ modelleri Xß`ya bağlı olarak aşağıdaki özdeşlikler kullanılarak doğrusallaştırııır (linearize edilir) [19].

$$
\begin{aligned}
& \log h(t \mid X)=\log h(t)+X \beta \\
& \log H(t \mid X)=\log H(t)+X \beta
\end{aligned}
$$

- Hızlandırılmış başarısızlık (ölüm) zamanı (HBZ)

$$
S(t \mid X)=\psi\left((\log (t)-X \beta) / \sigma^{\prime}\right)
$$

Buradaki $\psi$ standardize sağkalım dağılımı iken $\sigma$ ölçek (scale) parametresi olarak adlandırımaktadır.

Bu ilişki şöyle de ifade edilebilir;

$$
\log (T)=X \beta+\sigma^{\prime} \epsilon
$$

Burada $\epsilon, \psi$ dağılımın bir rassal değişkenidir.

HBZ modeli daha çok orantısallığın zorlandığı $(\mathrm{OH})$ durumlarda $\mathrm{COH}$ hatta $\mathrm{POH}$ yerine önerilen modellerdir [19].

Üstel regresyon katsayıları ( $\beta$ )'lar yani $\exp (\beta)^{\prime}$ lar, $\mathrm{COH}$ ve $\mathrm{POH}$ modellerinde $\mathrm{HO}$ olarak yorumlanırken, HBZ modellerinde ZO (zaman oranı) olarak yorumlanır. Zaman oranı (ZO), deneklerin sağkalım eğrisinde katettiği mesafenin oranlarının bir karşılaştırmasıdır. 0 zamanında \%100 sağkalım ile başlayan bir sağkalım fonksiyonu zaman arttıkça \%0 sağkalım yönünde iniş gösterir. Hızlandırıımış başarısızlık (ölüm) zamanı (HBZ) modelindeki sağkalım eğrisinde herkesin "başlangıç çizgisi" aynıdır, ancak bu eğiride bazı deneklerin diğerlerine göre daha hızlı ilerlemesi söz konusu olabilir. Diğer bir deyişle, bazı ortak değişkenlerin sağkalım eğrisindeki ilerlemeyi daha da hızlandırdığı yönünde bir etki gösterdikleri söylenebilir. Örneğin sürekli bir değişken söz konusu olduğunda ZO'nun 0,75 olması, değişkendeki her bir birimlik artışın sağkalım eğrisindeki ilerleyişini 0,25 daha aza indirerek etki etmesi şeklinde ortaya çıkar. Diğer bir açıdan, bir ortak değişkenin ZO değeri; ZO>1 
ise, bu durumun yavaşladığını veya olayın süresini uzattığını ima eder, buna karşın $Z 0<1$ ise, önceki olayın ortaya çıkmasının daha olası olduğunu gösterir [5].

\section{Bulgular}

Erken evre meme kanserli 697 kadına ait sağkalım verilerinde; sağkalanlar $n=537$ (\%77), ölenler n=160 (\%23)'tür. Ortalama izlem süresi 122 ay (3 ay-277 ay)'dır. Erken evre meme kanseri hastalarına ait Kaplan-Meier yöntemi ile genel sağkalım olasılıkları, 5 yıl için \%93,4, $10 \mathrm{yıl}$ için ise $\% 79,8$ olarak bulunmuştur. Genel sağkalım fonksiyonu Şekil 1'de verilmiştir.

Tek değişkenli analiz için yaş grupları, menopoz, histoloji, tümör lokalizasyonu, tümör boyutu, metastatik lenf nodu sayısı, östrojen ve progesteron reseptörü durumu, multifokalite, Her-2, lenfatik ve vasküler invazyon, nöral invazyon, ekstra kapsül tutulumu ve tümörün derecesi (grade) gibi 13 bağımsız değişken ile yapılan tek değişkenli analizler (LogRank, Basit Cox regresyon) sonucunda istatistiksel olarak anlamlı çıkan değişkenler şöyledir; menopoz $(p=0,002)$, tümörün derecesi (grade) $(p=0,032)$, multifokal $(p=0,05)$, lenfatik ve vasküler invazyon $(p<0,0001)$, nöral invazyon $(p=0,006)$, ekstra kapsül tutulumu $(p<0,0001)$, yaş grupları $(p<0,0001)$, tümör boyutu $(p=0,002)$ ve metastatik lenf nodu sayısı $(p<0,0001)$ (Tablo 1a, Tablo 1b). Bu değişkenlerden tümörün derecesi (grade), nöral invazyon, ekstra kapsül tutulumu ve yaş grupları değişkenlerine ait sağkalım eğrileri (fonksiyonları) orantılı hazarda sahip değillerdir (Şekil 2, Şekil 3, Şekil 4 ve Şekil 5).

Yaş grupları, tümör derecesi, nöral invazyon ve ekstra kapsül tutulumu $\mathrm{COH}$ varsayımını sağlamamasına rağmen, tek değişkenli analiz sonrası istatistiksel olarak anlamlı çıkan 9 bağımsız değişkene çok değişkenli $\mathrm{COH}$ modeli uygulandığında sadece metastatik lenf

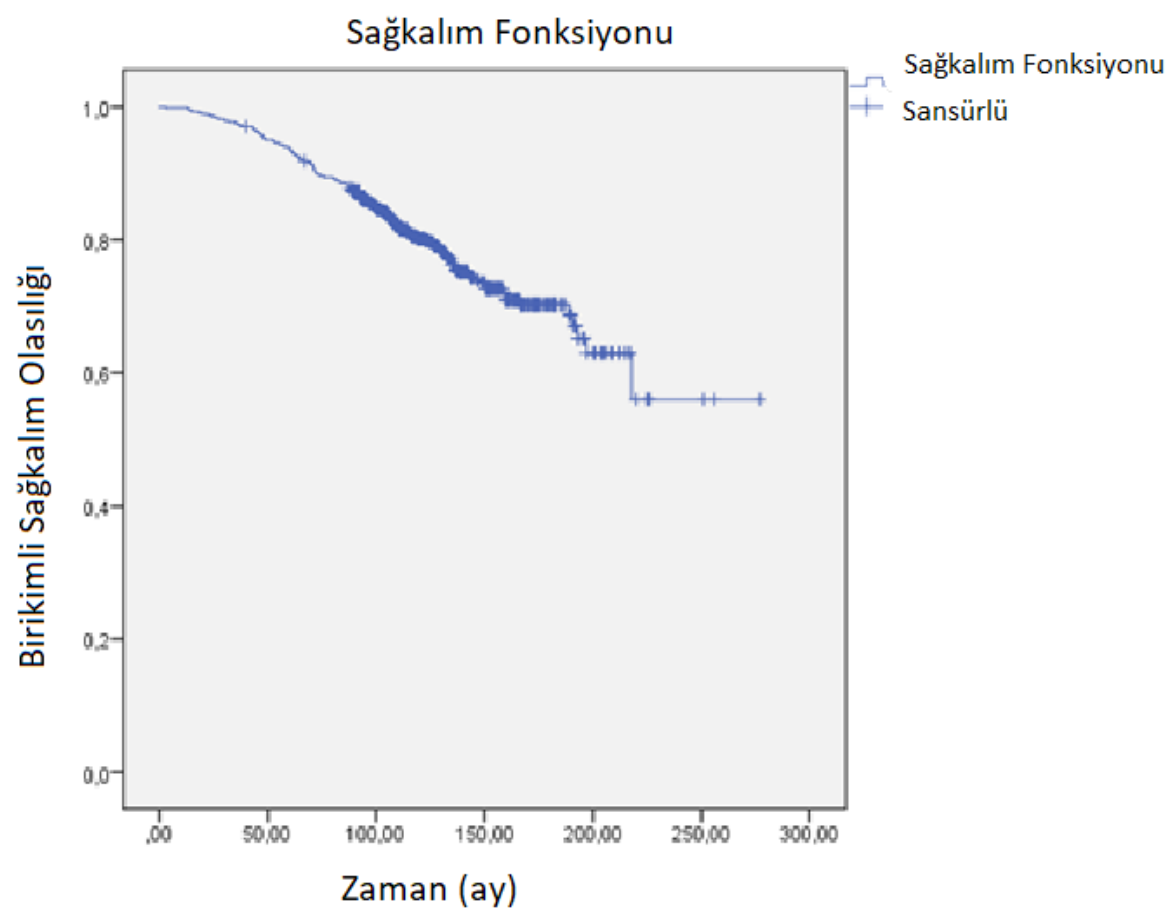

Şekil 1. Genel sağkalım fonksiyonu 


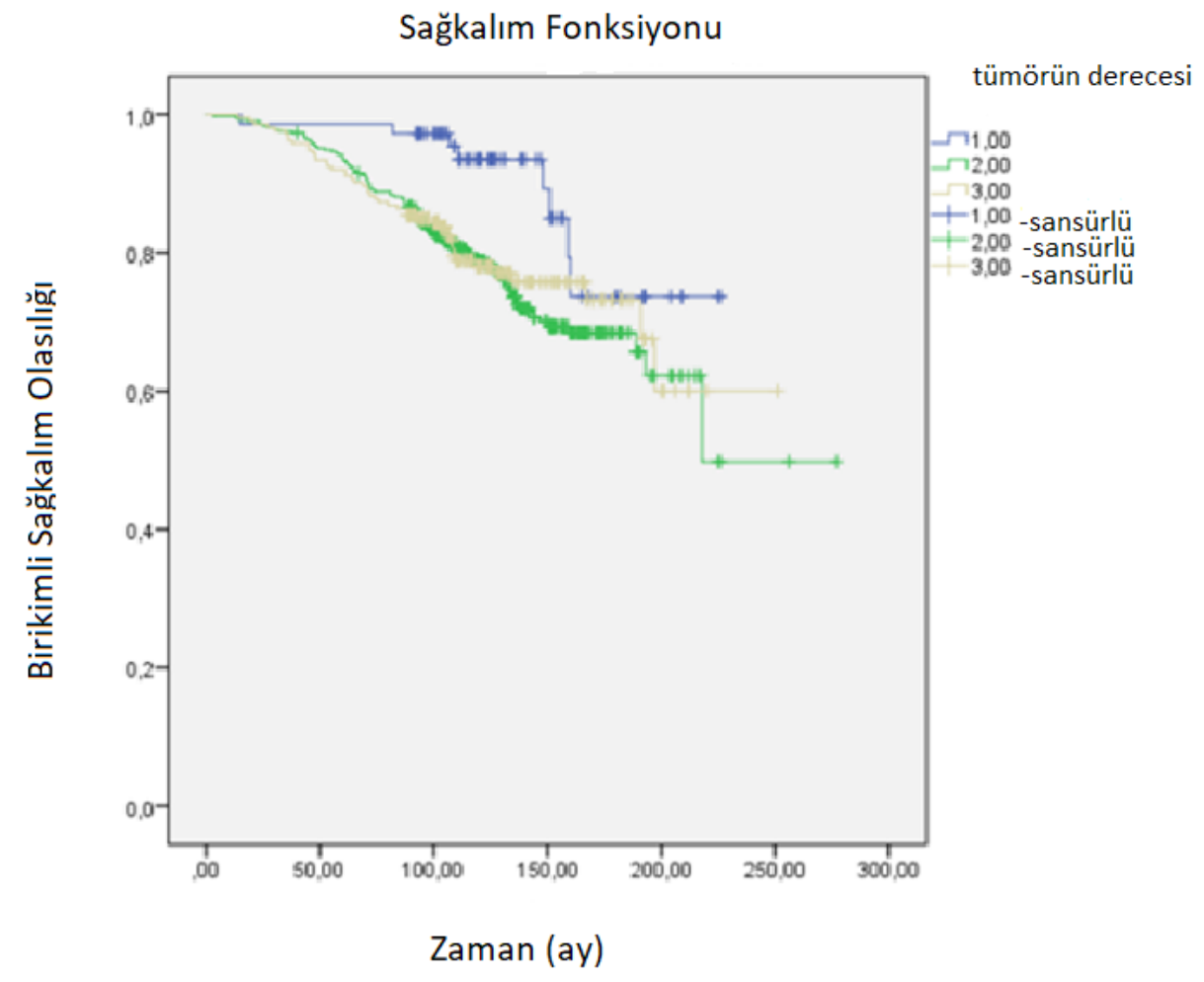

Şekil 2. Tümörün derecesine (grade) ait sağkalım eğrisi

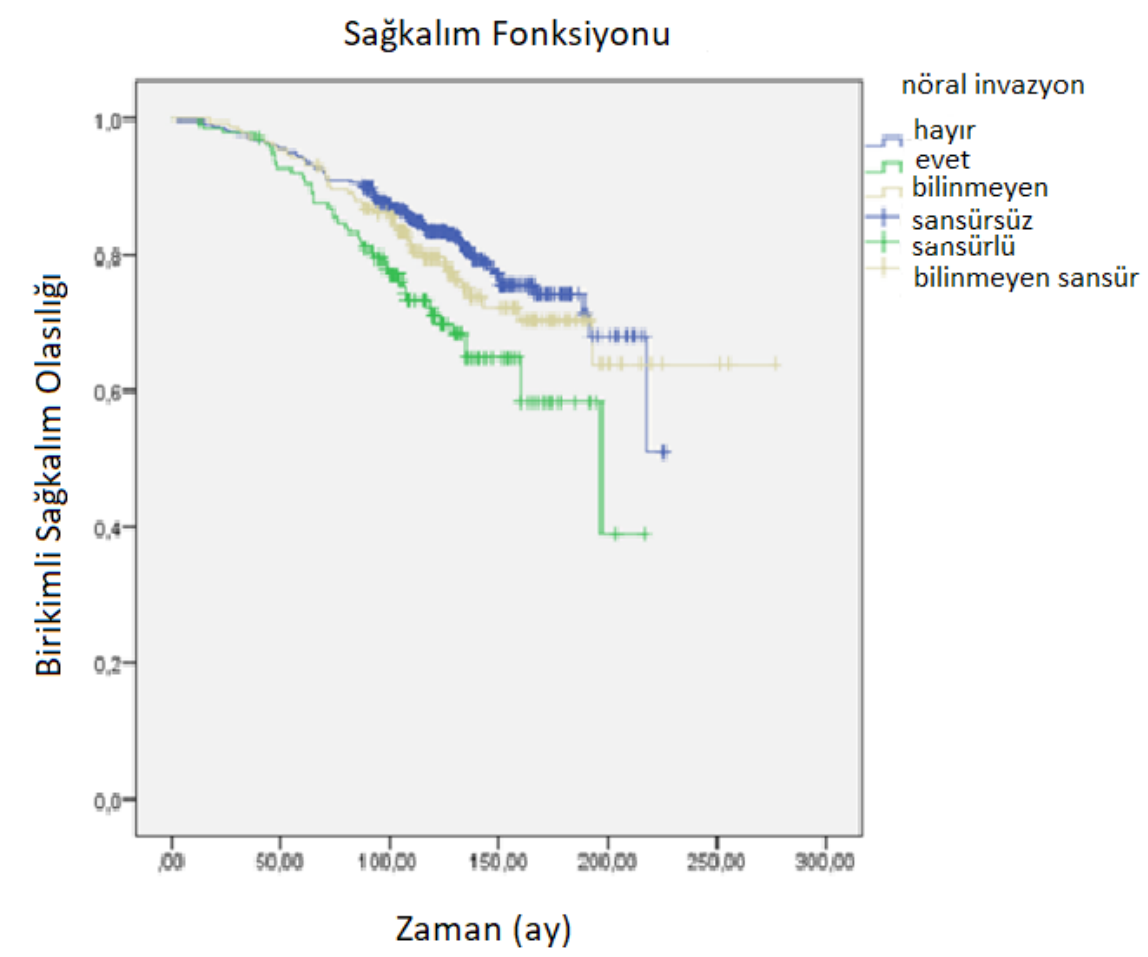

Şekil 3. Nöral invazyona ait sağkalım eğrisi 


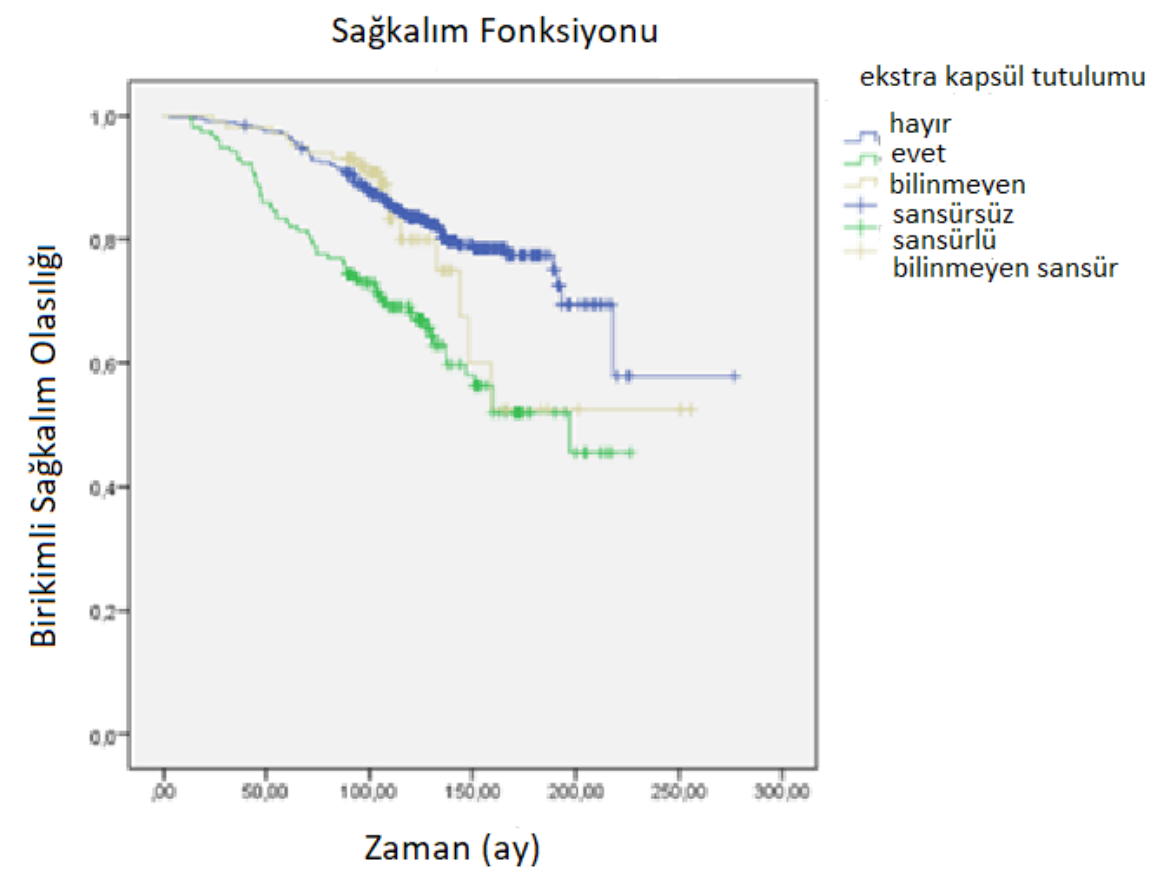

Şekil 4. Ekstra kapsül tutulumuna ait sağkalım eğrisi

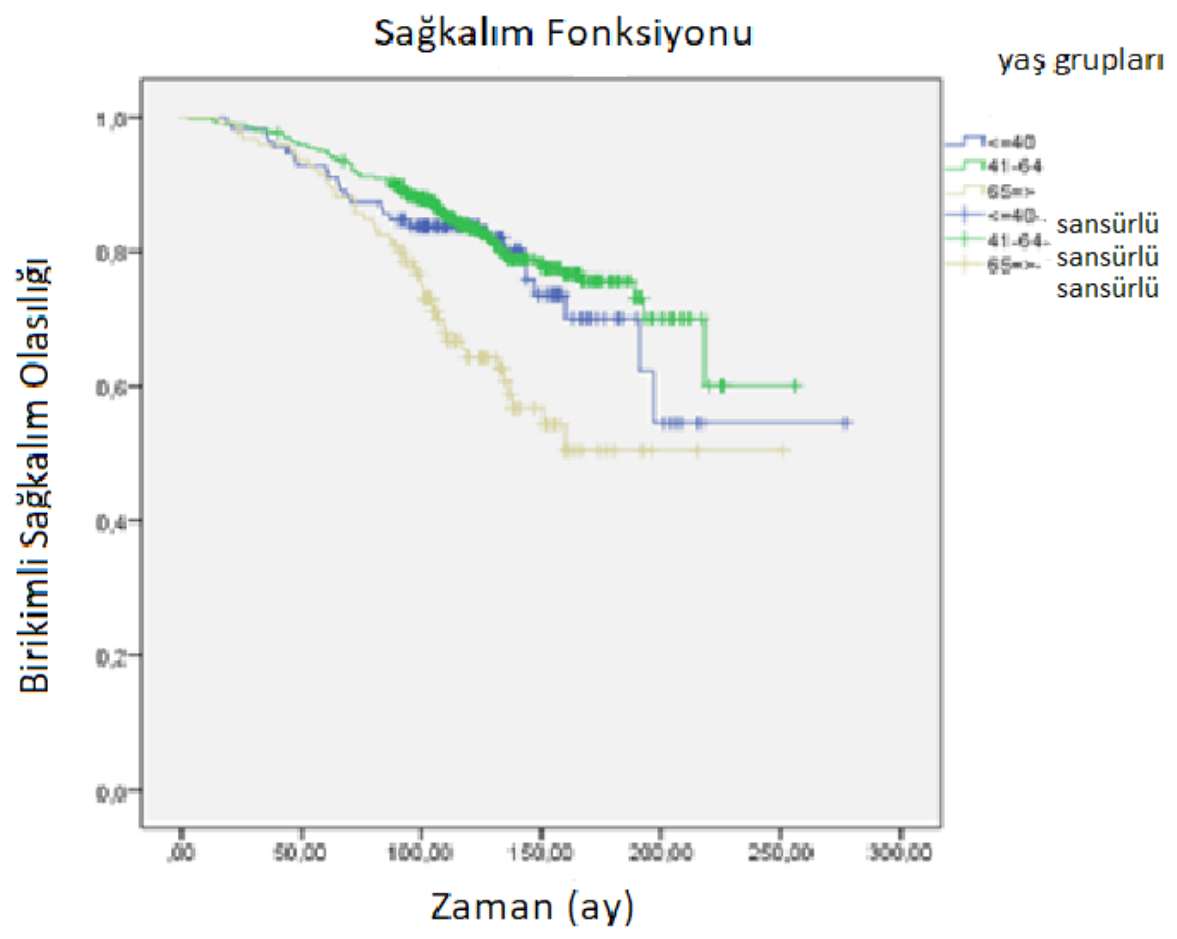

Şekil 5. Yaş gruplarına ait sağkalım eğrisi 
Tablo 1a. Sağkalım analizinde kesikli değişkenler için tek değişkenli analiz sonuçları

\begin{tabular}{|c|c|c|c|c|}
\hline Kesikli değişkenler & Ortalama \pm Standart Hata & \%95 Güven Aralığı & Log Rank x² & $p$ değeri \\
\hline $\begin{array}{l}\text { Yaş grupları } \\
\qquad=40(n=111) \\
\qquad 1-64(n=461) \\
65=>(n=125)\end{array}$ & $\begin{array}{l}210,363 \pm 11,913 \\
209,600 \pm 5,547 \\
175,026 \pm 8,791\end{array}$ & $\begin{array}{l}(187,014,233,713) \\
(198,727,220,473) \\
(157,796,192,256)\end{array}$ & 21,459 & $<0,0001$ \\
\hline $\begin{array}{l}\text { Menopoz } \\
\qquad \begin{array}{l}\operatorname{Var}(n=371) \\
\text { Yok }(n=326)\end{array}\end{array}$ & $\begin{array}{l}191,710 \pm 6,000 \\
224,564 \pm 9,426\end{array}$ & $\begin{array}{l}(179,949,203,471) \\
(206,089,243,039)\end{array}$ & 9,261 & 0,002 \\
\hline $\begin{array}{l}\text { Tümör lokalizasyonu } \\
\text { Sağ meme }(n=322) \\
\text { Sol meme }(n=372)\end{array}$ & $\begin{array}{l}217,973 \pm 9,237 \\
195,422 \pm 5,443\end{array}$ & $\begin{array}{l}(199,868,236,079) \\
(184,754,206,090)\end{array}$ & 0,639 & 0,424 \\
\hline $\begin{array}{l}\text { Multifokalite } \\
\text { Multifokal }(n=112) \\
\text { Tek lezyon }(n=585)\end{array}$ & $\begin{array}{l}173,706 \pm 7,431 \\
215,155 \pm 6,558\end{array}$ & $\begin{array}{l}(159,141,188,271) \\
(202,300,228,009)\end{array}$ & 3,854 & 0,050 \\
\hline $\begin{array}{ll}\text { Her-2 } & \\
& \text { Negatif }(n=364) \\
& \text { Pozitif } 1(n=44) \\
& \text { Pozitif } 2(n=51) \\
& \text { Pozitif } 3(n=73) \\
& \text { Her-2 bilinmiyor }(n=165)\end{array}$ & $\begin{array}{l}181,591 \pm 7,047 \\
160,801 \pm 7,153 \\
181,557 \pm 7,836 \\
156,269 \pm 8,183 \\
215,065 \pm 8,029\end{array}$ & $\begin{array}{l}(167,778,195,403) \\
(146,782,174,820) \\
(166,199,196,915) \\
(140,230,172,307) \\
(199,328,230,803)\end{array}$ & 4,599 & 0,331 \\
\hline $\begin{array}{l}\text { Lenfatik vasküler invazyon } \\
\text { Pozitif }(n=258) \\
\text { Negatif }(n=327) \\
\text { Bilinmiyor }(n=112)\end{array}$ & $\begin{array}{l}165,734 \pm 4,883 \\
196,672 \pm 3,811 \\
210,502 \pm 10,774\end{array}$ & $\begin{array}{l}(156,163,175,304) \\
(189,202,204,142) \\
(189,385,231,619)\end{array}$ & 21,827 & $<0,0001$ \\
\hline $\begin{array}{l}\text { Nöral invazyon } \\
\text { Pozitif }(n=138) \\
\text { Negatif }(n=385) \\
\text { Bilinmiyor }(n=174)\end{array}$ & $\begin{array}{l}162,901 \pm 6,781 \\
189,412 \pm 3,862 \\
217,731 \pm 8,840\end{array}$ & $\begin{array}{l}(149,611,176,192) \\
(181,842,196,983) \\
(200,404,235,058)\end{array}$ & 10,244 & 0,006 \\
\hline $\begin{array}{l}\text { Ekstra kapsül tutulumu } \\
\text { Pozitif }(n=156) \\
\text { Negatif }(n=440) \\
\text { Bilinmiyor }(n=101)\end{array}$ & $\begin{array}{l}158,207 \pm 6,837 \\
222,566 \pm 8,014 \\
192,632 \pm 14,197\end{array}$ & $\begin{array}{l}(144,807,171,607) \\
(206,860,238,273) \\
(164,805,220,459)\end{array}$ & 29,284 & $<0,0001$ \\
\hline $\begin{array}{l}\text { Tümörün derecesi (grade) } \\
\qquad \begin{array}{l}\text { G1 }(n=72) \\
\text { G2 }(n=412) \\
\text { G3 }(n=213)\end{array}\end{array}$ & $\begin{array}{l}202,656 \pm 7,516 \\
206,866 \pm 8,522 \\
199,353 \pm 7,369\end{array}$ & $\begin{array}{l}(187,925,217,388) \\
(190,164,223,569) \\
(184,910,213,796)\end{array}$ & 6,857 & 0,032 \\
\hline $\begin{array}{l}\text { Histoloji } \\
\text { İnfiltratif duktal ca }(n=514) \\
\text { İnvaziv lobüler ca }(n=62) \\
\text { Mixed }(n=61) \\
\text { Tubuler }(n=5) \\
\text { Medüller ca }(n=14) \\
\text { Müsinöz ca }(n=12) \\
\text { Papiller ca }(n=14) \\
\text { İnvaziv skuamöz ca }(n=3) \\
\text { Metaplastik ca }(n=3) \\
\text { Metaplastik ca }(n=2) \\
\text { İnfiltratif apokrin ca }(n=7)\end{array}$ & $\begin{array}{l}216,508 \pm 5,422 \\
184,516 \pm 8,917 \\
147,209 \pm 6,646 \\
189,000 \pm, 000 \\
175,643 \pm 6,126 \\
148,589 \pm 7,665 \\
172,339 \pm 11,412 \\
151,000 \pm 25,456 \\
89,000 \pm 28,577 \\
217,000 \pm, 000 \\
141,786 \pm 16,340\end{array}$ & $\begin{array}{l}(205,880,227,135) \\
(167,039,201,992) \\
(134,182,160,235) \\
(189,000,189,000) \\
(163,636,187,650) \\
(133,564,163,613) \\
(149,971,194,707) \\
(101,107,200,893) \\
(32,988,145,012) \\
(217,000,217,000) \\
(109,759,173,813)\end{array}$ & 7,612 & 0,667 \\
\hline $\begin{array}{l}\text { Östrojen ve progesteron } \\
\text { reseptörü durumu } \\
\text { ER+PR+(n=447) } \\
\text { ER+PR- }(n=61) \\
\text { ER-PR+(n=39) } \\
\text { ER-PR- }(n=139) \\
\text { ER+PR Bilinmiyor }(n=5)\end{array}$ & $\begin{array}{l}202,908 \pm 4,466 \\
172,775 \pm 8,132 \\
175,316 \pm 11,284 \\
184,999 \pm 6,317 \\
173,800 \pm 29,346\end{array}$ & $\begin{array}{l}(194,155,211,661) \\
(156,836,188,713) \\
(153,200,197,432) \\
(172,618,197,380) \\
(116,282,231,318)\end{array}$ & 3,608 & 0,729 \\
\hline
\end{tabular}


Tablo 1b. Sağkalım analizinde sürekli değişkenler için tek değişkenli analiz sonuçları

\begin{tabular}{lllll}
\hline Sürekli değişkenler* & HR & \% Güven Aralığı & $x^{2}$ & $p$ değeri \\
\hline Tümör boyutu & 1,133 & $(1,048,1,225)$ & 9,903 & 0,002 \\
Metastatik lenf nodu sayısı & 1,096 & $(1,072,1,121)$ & 72,771 & $<0,0001$ \\
\hline
\end{tabular}

*Tek değişkenli Cox orantılı hazard regresyon modeli ile hesaplanmıştır

nodu sayısı ve menopoz değişkenleri anlamlı bulunmuştur (Tablo 2).

Meme kanserinde, kanserin koltuk altındaki kaç lenf düğümüne sıçramış olduğu önemli bir göstergedir, ancak kanserin kan ve lenf yolu ile diğer organlara yayılmasını gösteren metastatik lenf nodu sayısı, her ne kadar ölenlerde sağkalanlara göre göreceli olarak daha yüksek olsa da, zaten riskin her iki gruptada da (sağkalan/ölen) yüksek boyutta olduğuna işaret eder. Bu nedenle, metastatik lenf nodu sayısına ait sağkalım hazardı $(\mathrm{HO}=1,080)$ yaklaşık 1 civarında kalmıştır. Diğer anlamlı bir değişken olan menopozda ise, menopoza giren meme kanseri hastalarının menopoza girmeyen meme kanseri hastalarına göre yaklaşık 1,6 kat daha fazla $(\mathrm{HO}=1,586)$ risk altında oldukları söylenebilir.

Hızlandırıımış Başarısızlık (ölüm) Zamanı (HBZ) Modeli için, bağımlı değişken olan genel sağkalım değişkenine ait log-normal, loglojistik, Weibull ve üstel dağılımlarının Hazard Fonksiyon'larına bakılmıştır. Log-normal, loglojistik, Weibull ve üstel dağılımlar için AIC değerleri sırasıyla; 867,26, 860,78, 864,86, 906,04 'dür. AIC değerine ve en iyi hazard fonksiyonu dağılımlarına göre en uygun HBZ modelinin, log-lojistik Hızlandırılmış Başarısızlık (Ölüm) Zamanı Modeli olduğu görülmüştür.

Log-lojistik Hızlandırılmış Başarısızlık (Ölüm) Zamanı (HBZ) regresyon modeli için elde edilen sonuçlar Tablo 3'de verilmiştir. Log-lojistik HBZ regresyonu sonucunda metastatik lenf nodu sayısı, menopoz ve tümör boyutu değişkenleri anlamlı çıkmıştır.

$\mathrm{Bu}$ sonuçlara göre; metastatik lenf nodu sayısı için ZO yaklaşık \%70 $(0,702)$ olarak hesaplanmıştır, dolayısıyla metastatik lenf nodu sayısı fazla olan olgularda sağkalım süresinin, metastatik lenf nodu sayısı az olanlara göre yüzde 30 daha kısa olduğu tahmin edilmektedir. Hatta ZO'nun güven aralığına dayanarak; $\% 20(1-0,803=0,197)$ ile $\% 39(1-0,613=0,387)$ arasında sağkalım süresinin kısalacağı söylenebilir.

Aynı şekilde; menopoz için ZO yaklaşık $\% 77(0,772)$ 'dir. Menopoza giren hastaların sağkalım sürelerinin, menopoza giremeyen hastalara göre yaklaşık \%23 daha kısa olduğu tahmin edilmektedir. ZO'nun güven aralığına göre; yaklaşık \%39 $(1-0,608=0,392)$ ile $\% 2$ $(1-0,980=0,02)$ arasında sağkalım süresinin kısalması mümkündür.

Tümör boyutu için ZO yaklaşık \%99 $(0,991)$ 'dur. Tümör boyutu yüksek olan meme kanseri hastalarına ait sağkalım süresinin, tümör boyutu düşük meme kanseri hastalarına göre \%1 daha kısa olduğu tahmin edilmektedir. ZO'nun güven aralığına göre; yaklaşık \%2 $(1-0,982=0,018)$ ile $\% 0,1 \quad(1-0,999=0,001)$ arasında sağkalım süresinin kısalması tahmin edilmektedir.

\section{Tartışma}

Meme kanseri günümüzde gelişmiş ve gelişmekte olan ülkelerde en sık görülen kanser tipidir [20-22]. Elbette erken tanı ile tedavide kayda değer başarılar sağlansa da, meme kanseri ve riskleri (hazard) üzerine sağkalım analizi çalışmaları halen büyük önem arzetmektedir.

Çalışmamızda erken evre meme kanserli hastalara çeşitli sağkalım hazard modelelleri uygulanmıştır. Birçok sağkalım analizi çalışmalarında $\mathrm{COH}$ modeli en çok tercih edilen seçenek olurken, varsayımların yerine getirilememesi nedeniyle, özellikle uzun dönem sağkalım çalışmalarında HBZ modellerinin uygulanması daha uygun olabilmektedir.

HBZ modeli ile yapılan sağkalım analizinde hangi modelin seçileceğine karar verebilmek için hazard verisini doğru analiz etmek gerekir. Zaman içinde hazard veya sağkalım oranı üzerine yorum tercihi, doğru bir modelleme ile sağlanır. 
Tablo 2. Cox Orantılı Hazard Regresyon Modeli sonuçları

\begin{tabular}{lllll}
\hline & & & \multicolumn{2}{l}{ HO (expß) için \%95 } \\
& & & \multicolumn{2}{l}{ Güven Aralığı } \\
& $p$ değeri & HO $=\operatorname{Exp}(B)$ & Alt & Üst \\
\hline Multifokal & 0,356 & 1,199 & 0,816 & 1,762 \\
lenfatik ve vasküler invazyon & 0,120 & 1,209 & 0,952 & 1,537 \\
tümör boyutu & 0,284 & 1,051 & 0,960 & 1,151 \\
Metastatik lenf nodu sayısı & 0,0001 & 1,080 & 1,053 & 1,108 \\
Menopoz & 0,005 & 1,586 & 1,146 & 2,194 \\
yaş grupları & 0,202 & 1,230 & 0,895 & 1,690 \\
nöral invazyonu & 0,591 & 0,944 & 0,765 & 1,165 \\
ekstra kapsül tutulumu & 0,379 & 1,111 & 0,879 & 1,406 \\
tümör derecesi & 0,562 & 1,082 & 0,829 & 1,413 \\
\hline
\end{tabular}

Tablo 3. Log-lojistik Hızlandııımış Başarısızlık (ölüm) Zamanı (HBZ) regresyon modeli sonuçları

\begin{tabular}{|c|c|c|c|c|}
\hline & \multirow[b]{2}{*}{$p$ değeri } & \multirow[b]{2}{*}{$Z O=\operatorname{Exp}(B)$} & \multicolumn{2}{|c|}{$\begin{array}{l}\text { ZO }(\exp \beta) \text { için } \\
\% 95 \text { Güven Aralığı }\end{array}$} \\
\hline & & & Alt & Üst \\
\hline Multifokal & 0,393 & 0,897 & 0,796 & 1,119 \\
\hline lenfatik ve vasküler invazyon & 0,401 & 0,937 & 0,805 & 1,090 \\
\hline tümör boyutu & 0,037 & 0,991 & 0,982 & 0,999 \\
\hline Metastatik lenf nodu sayısı & 0,0001 & 0,702 & 0,613 & 0,803 \\
\hline Menopoz & 0,034 & 0,772 & 0,608 & 0,980 \\
\hline yaş grupları & 0,183 & 0,874 & 0,717 & 1,065 \\
\hline nöral invazyonu & 0,955 & 1,004 & 0,881 & 1,143 \\
\hline ekstra kapsül tutulumu & 0,470 & 0,947 & 0,818 & 1,097 \\
\hline tümör derecesi & 0,504 & 0,944 & 0,796 & 1,118 \\
\hline
\end{tabular}


Akaike bilgi kriteri ise, hazard ile ilgili $\mathrm{COH}$, $\mathrm{POH}$ ve HBZ modelleri gibi farklı varsayımlara dayanan rakip modelleri karşılaştırmak için kullanılır. Her ne kadar Bradburn ve ark. [15] model yeterliliğini değerlendirmek için çeşitli tekniklerlerden bahsetmiş olsalar da, AIC yine en tercih edilen ölçüt olduğundan çalışmamızda da biz AIC kullandık [23, 24].

Sağkalım analizinde etkin risk faktörleri ve onların hazard değerlerini doğru tahmin etmek ancak doğru modelleme ile sağlanır ve bu nedenle sağkalım analizlerinde orantısallığın denetimi kaçınılmazdır. Çalışmamızda orantısallığın bozulması nedeniyle $\mathrm{COH}, \mathrm{POH}$ modellerinin uygulanması zora girdiğinden HBZ modeli bir seçenek olarak sunulmuş ve uygulanmıştır. $\mathrm{COH}$ modelindeki $\mathrm{OH}$ varsayımı sağlanmamasına rağmen, tek değişkenli analiz sonrası istatistiksel olarak anlamlı çıkan 9 bağımsız değişken çok değişkenli $\mathrm{COH}$ modeline girdiğinde sadece metastatik lenf nodu sayısı ve menopoz değişkenleri anlamlı çıkmıştır. Oysa, söz konusu 9 bağımsız değişken Log-lojistik $\mathrm{HBZ}$ regresyon modeline girdiğinde, $\mathrm{COH}$ modeli uygulamasında da anlamlı çıkan metastatik lenf nodu sayısı ve menopoz değişkenlerine tümör boyutu değişkeni de eklenerek anlamlı çıkmıştır. Dolayısıyla risk faktörlerinin tespiti ve risk tahmin değerlerinin doğru saptanabilmesi için model varsayımlarının dikkate alınması ve doğru modelleme yapılması büyük önem arz etmektedir.

Bildiğimiz kadarıyla meme kanserli hastalarda alanında HBZ modeli ile çok az sayıda yapılan çalışma bulunmaktadır [3, 25, 26]. Karimi ve ark. [3], yaklaşık 7 yıllık İranlı meme kanseri hastası üzerinde yaptığı çalışmada, en iyi HBZ modellerin Genelleştirilmiş Gamma ve Weibull olduğunu göstermiştir. Ghorbani ve ark. [25] ise yine 8 yıl boyunca takip edilmiş olan İranlı meme kanserli kadınlarda Weibull dağılımı ile HBZ modelini gerçekleştirmiştir. Iraji ve ark. [26] 9 yıl süreyle Doğu Azerbayjan popülasyonundaki meme kanserli hastalarda Log-normal modelinin en uygun model olduğunu belirtmiştir. Bu çalışmada ise HBZ modeli Loglojistik ile en uygun model olarak tesbit edilmiştir. Bizim çalışmamızın diğer çalışmalardaki HBZ modellerinde kullanılan hazard dağılımından farklı olmasını, çalışmamızın daha uzun takibe sahip olması şeklinde açıklayabiliriz. Bunun yanında, tüm çalışmalarda ortak görülen nokta ise tümör varlığının/boyutunun yaşam süresini kısalttığı üzerinedir. Ayrıca, Alfonso ve de Oca [27] Genelleştirilmiş Gamma modelinin meme kanserine en uygun modelleme olduğunu öngörmüşlerdir. Khan ve ark. [28] ise exponential ve Weibull modelinin Hispanik olmayan beyaz kadınlarda en iyi modelleme olduğunu iddia etmişlerdir. Meme kanserli hastalarda yapılan bu çalışmamızın, var olan istatistiksel modellere kuvvetli bir seçenek bif model olması bakımından önemli bir çalışma olduğunu düşünmekteyiz.

Çalışmamız literatürde az kullanılan HBZ modeli uygulamasına bir örnek teşkil etmesi açısından önemli bir çalışmadır, ancak çalışmamız tek merkeze ait bir çalışmadır. Çok merkezli ve dolayısıyla örnek sayısı daha fazla olan bir veri tabanına ait erken evre meme kanseri sağkalım analizi sonuçlarının hastalığın gelişimi ve tedavisinde daha bilgilendirici olacağı da bir gerçektir.

Sonuç olarak, sağkalım analizleri söz konusu olduğunda literatürde $\mathrm{COH}$ modeli en sık kullanılan modellerin başında gelir. Özellikle $\mathrm{COH}$ modellerinde, ortak değişkenler için hazardların orantılı olmasının önemi büyüktür; hazardların orantılı olmadığı durumlarda $\mathrm{COH}$ regresyon modeli yerine HBZ regresyon modeli gibi modellerin kullanımı daha uygun olabilir.

Unutmamalıdırki, HBZveCOHmodellerinden elde edilen parametrelerin yorumu farklıdır. $\mathrm{COH}$ modellerinde hazardlar karşılaştırılmaktayken, HBZ modellerinde sağkalım zamanlarının (sürelerinin) karşılaştırması yapılmaktadır.

Biyoistatistik uzmanları olarak, sağkalım analizlerinin özellikle planlama aşamasından başlayarak ilgili araştırmacılara $\mathrm{COH}$ regresyon modellerinin dışında uygun koşullarda daha doğru analiz ve yorum olanağı sağlayan HBZ gibi daha başkaca modellerin önerilmesi gerektiğini düşüyoruz.

Çıkar ilişkisi: Yazarlar çıkar ilişkisi olmadığını beyan eder.

\section{Kaynaklar}

1. Cox DR. Regression models and Life-Tables. Breakthroughs in statistics. Springer Series in Statistics, New York, NY, 1992:527-541. https://doi. org/10.1007/978-1-4612-4380-9 
2. Lee ET, Go OT. Survival analysis in public health research. Annu Rev Public Health 1997;18:105-134. https://doi.org/10.1146/annurev.publhealth.18.1.105

3. Karimi A, Delpisheh A, Sayehmiri K. Application of accelareted failure time models for breast cancer patients' survival in Kurdistan Province of Iran. J Cancer Res Ther 2016;12:1184-1188. https://doi. org/10.4103/0973-1482.168966

4. Keene ON. Alternatives to the hazard ratio in summarizing efficacy in time-to-event studies: an example from influenza trials. Stat Med 2002;21:36873700. https://doi.org/10.1002/sim.1312

5. Khanal SP, Sreenivas V, Acharya SK. Accelarated failure time models: an application in the survival of acute liver failure patients in India. IJSR 2014;3:161166. Available at: https://www.ijsr.net/search_index results_paperid.php?id=201445. Accessed March 5, 2021

6. Bakhshi E, Khoei RAA, Azarkeivan A, Kooshesh M, Biglarian A. Survival analysis of thalassemia major patients using Cox, Gompertz proportional hazard and Weibull accelerated failure time models. Med J Islam Repub Iran 2017;31:97. https://doi.org/10.14196/ mjiri.31.97

7. Ghadimi M, Mahmoodi M, Mohammad K, Zeraati H, Rsouli M, Sheikhfathollahi M. Family history of the cancer on the survival of the patients with gastrointestinal cancer in northern Iran, using frailty models. Bio Med Central Gastroenterol 2011;11:104. https://doi.org/10.1186/1471-230X-11-104

8. George B, Seals S, Aban I. Survival analysis and regression models. J Nucl Cardiol 2014;21:686-694. https://doi.org/10.1007/s12350-014-9908-2

9. Wei LJ. The accelerated failure time model: a useful alternative to the Cox regression model in survival analysis. Stat Med 1992;11:1871-1879 https://doi. org/10.1002/sim.4780111409

10. Pourhoseingholi MA, Hajizadeh E, Dehkordi BM, Safaee A, Abadi A, Zali MR. Comparing Cox regression and parametric models for survival of patients with gastric carcinoma. Asian Pac J Cancer Prev 2007;8:412-416.

11. Swindell WR. Accelerated failure time models provide a useful statistical framework for aging research. Exp Gerontol 2009;44:190-200. https://doi.org/10.1016/j. exger.2008.10.005

12. Kwong GPS, Hutton JL. Choice of parametric models in survival analysis: applications to monotherapy for epilepsy and cerebral palsy. Appl Statist 2003;52:153168. https://doi.org/10.1111/1467-9876.00395

13. Seyoum D, Degryse JM, Kifle YG, et al. Risk factors for mortality among adult HIVIAIDS patients following antiretroviral therapy in southwestern ethiopia: an assessment through survival model. Int J Environ Res Public Health 2017;14:296. https://doi.org/10.3390/ ijerph14030296
14. Teshnizi SH, Ayatollahi SMT. Comparison of Cox regression and parametric models: application for assessment of survival of pediatric cases of acute leukemia in southern Iran. Asian Pac J Cancer Prev 2017;18:981-985. https://doi.org/10.22034/ APJCP.2017.18.4.981

15. Bradburn MJ, Clark TG, Love SB, Altman DG. Survival analysis part II: multivariate data analysis - an introduction to concepts and methods. $\mathrm{Br} \mathrm{J}$ Cancer 2003;89:431-436. https://doi.org/10.1038/ sj.bjc. 6601119

16. Akaikei H. Information Theory and an Extension of the Maximum Likelihood Principle. Proc. 2nd Int. Symp. on Information Theory. 1973:267-281. https:// doi.org/10.1007/978-1-4612-1694-0_15. Accessed February 19, 2021

17. Vaida F, Blanchard S. Conditional akaike information for mixed-effects models. Biometrika 2005;92:351-370. https://doi.org/10.1093/biomet/92.2.351

18. Vahedi M, Mahmoodi M, Mohammad K, Ossareh S, Zeraati $\mathrm{H}$. What is the best parametric survival models for analyzing hemodialysis data? Glob J Health Sci 2016;8:56161. https://doi.org/10.5539/gjhs.v8n10p118

19. Bekiroğlu N, Cebeci IA, Hüseyin A, Acar M; Parametrik hızlandırılmış başarısızlık (ölüm) zamanı (HBZ) modelleri ile akciğer kanseri hastalarında uygulama (Poster sunumu). XX. Ulusal ve III. UluslararasI Biyoistatistik Kongresi. 26-29 Ekim 2018, Gaziantep. Available at: https://docplayer.biz.tr/116645614-Xxulusal-ve-iii-uluslararasi biyoistatistik-kongresi-bildirikitabi.html. Accessed March 3, 2021

20. Global Burden of Disease Cancer Collaboration. Fitzmaurice C, Allen C, Barber RM, et al. Global, regional, and national cancer incidence, mortality, years of life lost, years lived with disability, and disabilityadjusted life-years for 32 cancer groups, 1990 to 2015: a systematic analysis for the global burden of disease study. JAMA Oncol 2017;3:524-548. https:// doi.org/10.1001/jamaoncol.2016.5688

21. Bray F, Ferlay J, Soerjomataram I, Siegel RL, Torre LA, Jemal A. Global cancer statistics 2018: GLOBOCAN estimates of incidence and mortality worldwide for 36 cancers in 185 countries. CA Cancer J Clin 2018;68:394-424. https://doi.org/10.3322/ caac. 21492

22. Global Burden of Disease Cancer Collaboration. Fitzmaurice C, Akinyemiju TF, Al Lami FH, et al. Global, regional, and national cancer incidence, mortality, years of life lost, years lived with disability, and disabilityadjusted life-years for 29 cancer groups, 1990 to 2016: a systematic analysis for the global burden of disease study. JAMA Oncol 2018;4:1553-1568. https://doi. org/10.1001/jamaoncol.2018.2706 
23. Kasza J, Wraith D, Lamb K, Wolfe R. Survival analysis of time-to-event data in respiratory health research studies. Respirology 2014;19:483-492. https://doi. org/10.1111/resp.12281

24. Rubio FJ, Remontet L, Jewell NP, Belot A. On a general structure for hazard-based regression models: an application to population-based cancer research. Stat Methods Med Res 2019;28:2404-2417. https://doi. org/10.1177/0962280218782293

25. Ghorbani N, Yazdani Charati J, Anvari K, Ghorbani N. Application of weibull accelerated failure time model on the disease-free survival rate of breast cancer. Iran J Health Sci 2016;4:11-18. https://doi.org/10.18869/ acadpub.jhs.4.2.11

26. Iraji Z, Koshki TJ, Dolatkhah R, Jafarabadi MA. Parametric survival model to identify the predictors of breast cancer mortality: an accelerated failure time approach. J Res Med Sci 2020;25:38. https://doi. org/10.4103/jrms.JRMS_743_19

27. Alfonso AG, de Oca NAM. Application of hazard models for patients with breast cancer in Cuba. Int J of Clin Exp Med 2011;4:148-156.

28. Khan HMR, Saxena A, Gabbidon K, Stewart TSJ, Bhatt C. Survival analysis for white non-Hispanic female breast cancer patients. Asian Pac J Cancer Prev 2014;15:4049-4054. https://doi.org/10.7314/ apjcp.2014.15.9.4049

Teşekkür: Yazarlar olarak çalışmamızdaki verilerin kullanımına izin veren; Prof. Dr. Fulden Yumuk'a, Doç. Dr. Mehmet Akif Öztürk'e, Uzman Dr. Duygu Erbaş Saçar'a, Biyoistatistik Uzmanı Sinan Uzun'a teşekkürlerimizi sunarız.
Etik kurul onayı: Bu araştırma, Marmara Üniversitesi Tıp Fakültesi Klinik Araştırmalar Etik Kurulu'nun 26.07.2019 tarihli ve 09.2019.687 sayılı onayı ile yapılmıştır.

\section{Yazarların makaleye olan katkıları}

N.B. çalışmanın ana fikrini, amacını kurgulamış, gereç ve yöntem bölümünü yazmıştır. N.B. ve A.Ü. bulgular kısmınındaki verilerin değerlendirmesini yapmış makalenin tartışma bölümünü yazmışlardır. Ayrıca A.Ü. kaynaklar bölümünü düzenlemiştir. N.B. ve A.Ü. tüm makaleyi gözden geçirip çalışmanın tamamını tartışmış, gerekli düzeltmeleri yapmış ve son halini onaylamıştır. 